\title{
Correction to: Developing a Model for Decision-Makers in Dynamic Modeling of Urban Water System Management
}

\author{
Keivan Karimlou ${ }^{1}$ - Nemat Hassani ${ }^{1}$ • Abdollah Rashidi Mehrabadi ${ }^{1}$. \\ Mohammad Reza Nazari ${ }^{2}$
}

Published online: 16 May 2020

(C) Springer Nature B.V. 2020

\section{Correction to: Water Resour Manag \\ https://doi.org/10.1007/s11269-019-02428-z}

The original version of this article unfortunately contains mistakes introduced during the publishing process.

In Figure 1 and all of the panels of figures 2 and 3 were incorrect. The corrected figures are shown on the next page.

The online version of the original article can be found at https://doi.org/10.1007/s11269-019-02428-z

Keivan Karimlou

k_karimlou@sbu.ac.ir

1 Faculty of Civil, Water \& Environmental Engineering, Shahid Beheshti University, P. O. Box 19835-196, Tehran, Iran

2 Department of Natural Resources and Environmental Economics, Environmental Sciences Research Institute, Shahid Beheshti University, G.C., P. O. Box 19835-196, Tehran, Iran 


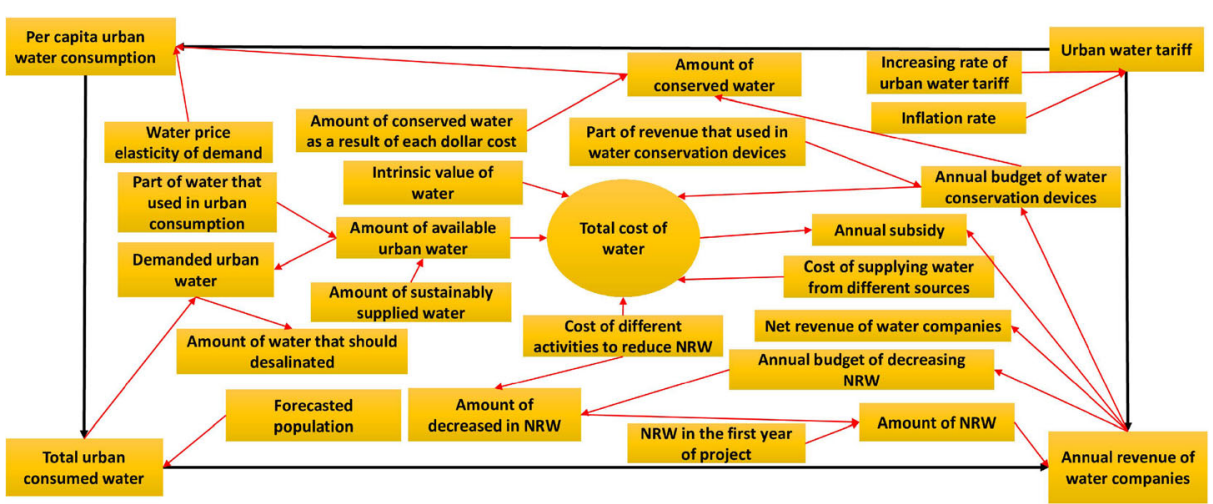

Fig. 1 The model, which is used in Vensim® model

a

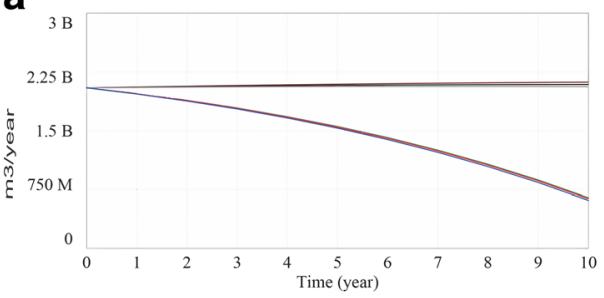

Scenario 6:

Scenario 5

Scenario 3 :

Scenario 2: b

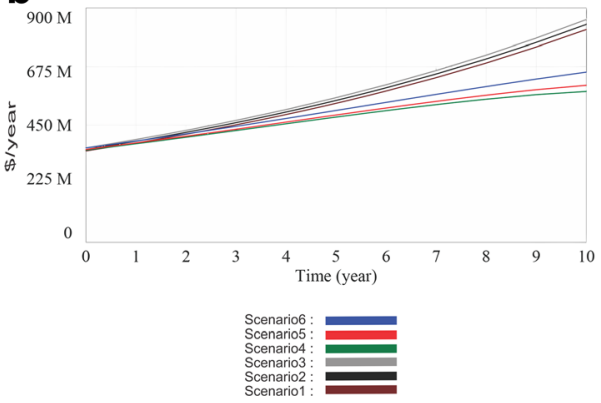

Fig. 2 Consequences of implementation of Scenarios (Aher et al. 1991) 6 on: a Water that should be supplied by Tehran water sources, b Subsidy that should be paid by water suppliers 
a

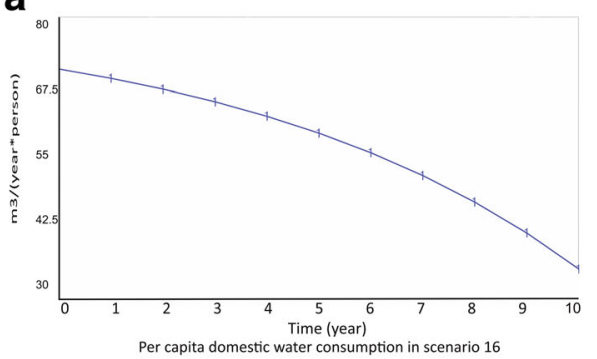

C

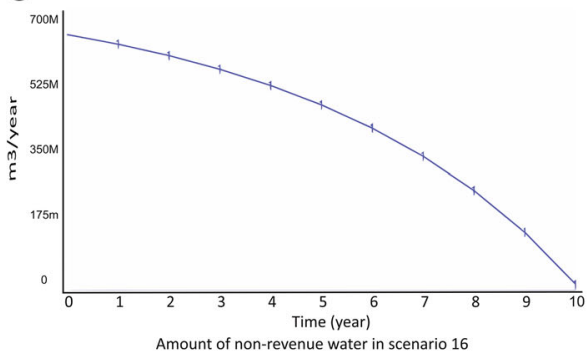

b
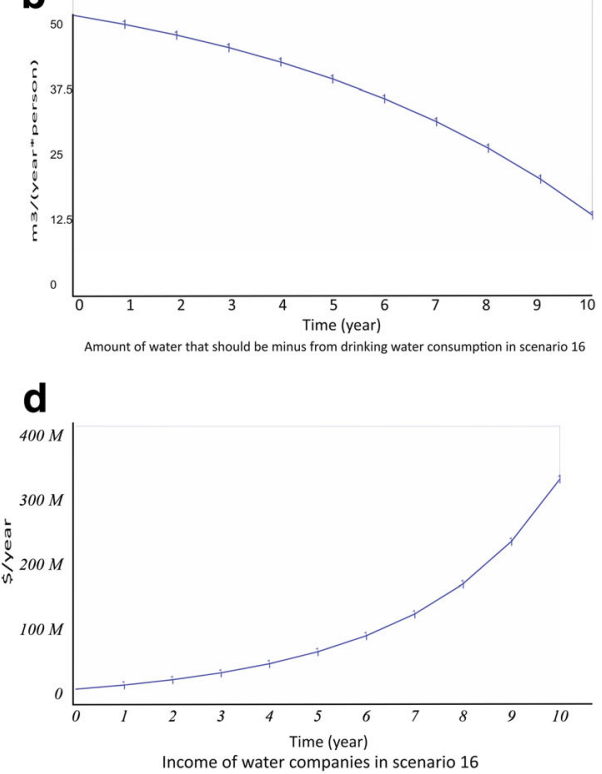

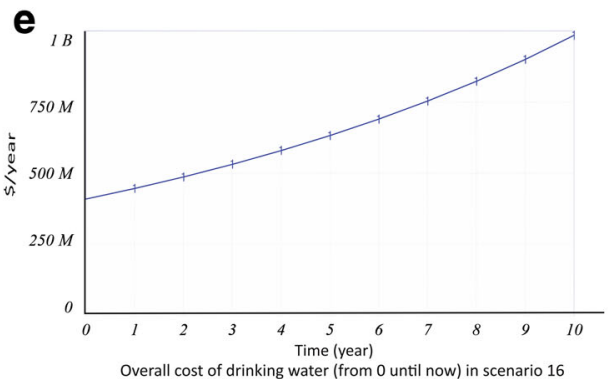

Fig. 3 a Per capita domestic water that is needed to be consumed in Scenario 17, b difference between per capita domestic water that is needed to be consumed in Scenario 17 and sustainably available domestic water, c amount of NRW, $\mathbf{d}$ income of water companies, e overall cost of domestic water

In the last sentence of section 4.1 (the best scenario) should be modified as follow:

"As both criteria in scenario 16 are less than the other scenarios in total period of study, scenario 17 is proposed as the best scenario out all." should be "As both criteria in scenario 16 are less than the other scenarios in the total period of study, scenario 16 is proposed as the best scenario out of all."

Publisher's Note Springer Nature remains neutral with regard to jurisdictional claims in published maps and institutional affiliations. 